\section{International Scientific Journal Theoretical \& Applied Science}

\author{
p-ISSN: 2308-4944 (print) e-ISSN: 2409-0085 (online) \\ Year: $2016 \quad$ Issue: 4 Volume: 36 \\ Published: $30.04 .2016 \quad$ http://T-Science.org
}

Svetlana Anatol'evna Balyaeva Professor, Doktor of Pedagogical Science,

Professor Department of Physics, State Maritime University Admiral Ushakov, Russia, allauglova@mail.ru

SECTION 21. Pedagogy. Psychology. Innovation in Education.

\title{
INFORMATION MODEL AS A MEANS OF FORMATION OF PROFESSIONAL INTEGRITY OF KNOWLEDGE OF MARITIME TRANSPORT
}

\author{
Abstract: Obtained principles of the system approach. Submitted by building the content of the discipline with \\ the system approach. Available information models in the form of structural models of knowledge and skills. \\ Key words: systemic approach, academic discipline, structural model of knowledge, skills structural model. \\ Language: Russian \\ Citation: Balyaeva SA (2016) INFORMATION MODEL AS A MEANS OF FORMATION OF \\ PROFESSIONAL INTEGRITY OF KNOWLEDGE OF MARITIME TRANSPORT. ISJ Theoretical \& Applied \\ Science, 04 (36): 141-143. \\ Soi: http://s-o-i.org/1.1/TAS-04-36-23 Doi: crossef http://dx.doi.org/10.15863/TAS.2016.04.36.23
}

УДК 372.851

\section{ИНФОРМАЦИОННЫЕ МОДЕЛИ КАК СРЕДСТВО ФОРМИРОВАНИЯ ЦЕЛОСТНОЙ СИСТЕМЫ ЗНАНИЙ СПЕЦИАЛИСТОВ МОРСКОГО ТРАНСПОРТА}

Аннотация: Выделены принципы системного подхода. Представлено построение содержания учебной дисичилины с позиичй системного подхода. Предлагаются информационнье модели в виде структурных моделей знания и умения.

Ключевые слова: системный подход, учебная дисциплина, структурная модель знания, структурная модель умения.

\begin{abstract}
Формирование целостной системы профессиональных знаний будущих специалистов морского транспорта в значительной степени определяется уровнем общенаучной подготовки. Для повышения эффективности цикла общенаучных дисциплин необходима перестройка содержания этих дисциплин и способов их усвоения на базе инновационных дидактических технологий
\end{abstract} $[1,2,3]$.

Возможность применения системного подхода к познавательным объектам основывается на системности как важнейшем качестве действительности. В научной литературе по общей теории систем [4,5] в качестве основополагающих принципов системного подхода выделены следующие:

- рассмотрение познавательного объекта как системы;
- определение состава, структуры и организации элементов и частей системы, обнаружение ве-дущих взаимодействий между ними;

- выявление внешних связей системы, определение функции системы и ее роли среди других систем;

- трехуровневое рассмотрение любого объекта и обнаружение на этой основе закономерностей и тенденций развития системы.

Данный подход принципиально позволяет выделить такую систему ориентиров и указаний, которая дает возможность использовать содержание каждой учебной дисциплины как методологического средства в дальнейшей учебной и профессиональной деятельности студентов, обеспечивает возможность реализовать педагогическую интеграцию содержания всех учебных дисциплин, участвующих в формировании специалиста, 


\section{Impact Factor:}

\begin{tabular}{lr|lr} 
ISRA $($ India $)$ & $=\mathbf{1 . 3 4 4}$ & SIS $($ USA $)$ & $=\mathbf{0 . 9 1 2}$ \\
ISI $($ Dubai, UAE) & $=\mathbf{0 . 8 2 9}$ & PИНЦ $($ Russia $)=\mathbf{0 . 2 3 4}$ \\
GIF $($ Australia $)$ & $=\mathbf{0 . 5 6 4}$ & ESJI $($ KZ $)$ & $=\mathbf{1 . 0 4 2}$ \\
JIF & $=\mathbf{1 . 5 0 0}$ & SJIF $($ Morocco $)$ & $=\mathbf{2 . 0 3 1}$
\end{tabular}

$\begin{array}{ll}\text { ICV (Poland) } & =\mathbf{6 . 6 3 0} \\ \text { PIF (India) } & =1.940 \\ \text { IBI (India) } & =4.260\end{array}$

создает условия для построения органически целостной системы професси-ональной

\section{СТРУКТУРНАЯ МОДЕЛЬ ЗНАНИЯ}
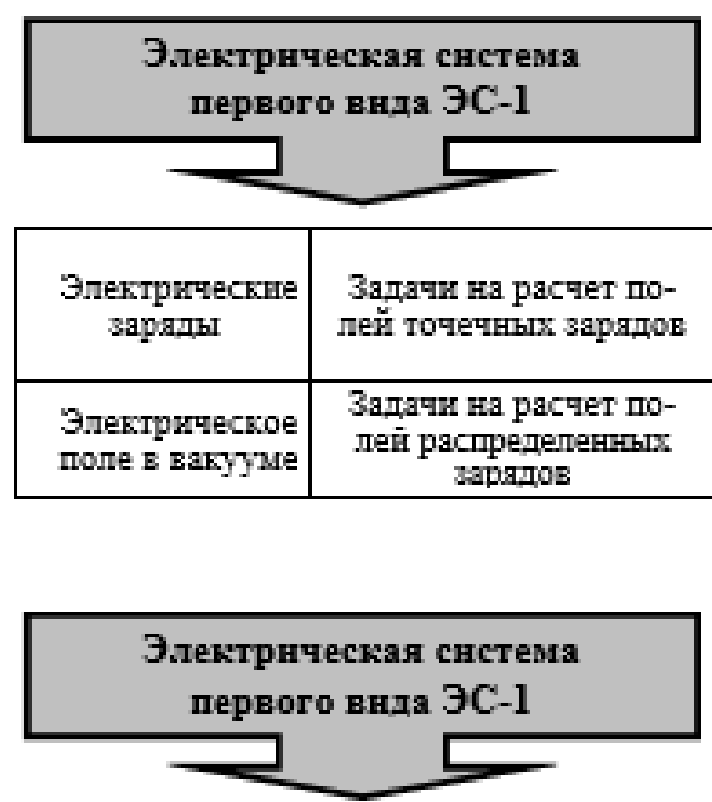

\begin{tabular}{|c|c|}
\hline \multicolumn{2}{|c|}{ ЭС-1 Структурные э.тементы } \\
\hline \multirow{2}{*}{$\begin{array}{l}\text { Неподвгқыные } \\
\text { зарақенные } \\
\text { объекты }\end{array}$} & Точентые заряды \\
\hline & $\begin{array}{l}\text { Распределенные } \\
\text { зарлды }\end{array}$ \\
\hline \multicolumn{2}{|c|}{$\begin{array}{c}\text { Снстемообразуюшне отношення } \\
\text { в ЭС-1 } \\
\end{array}$} \\
\hline \multirow[b]{2}{*}{ Спповые } & $\begin{array}{l}\text { Oсновная харахтери- } \\
\text { стика: напракен- } \\
\text { ность }\end{array}$ \\
\hline & $\begin{array}{l}\text { Основные законы: } \\
\text { - закон Кулона; } \\
\text { - принцип супер- } \\
\text { позици }\end{array}$ \\
\hline \multirow[b]{2}{*}{$\begin{array}{l}\text { Энергети- } \\
\text { ческие }\end{array}$} & $\begin{array}{l}\text { Основная характерн- } \\
\text { стика: потенщиал }\end{array}$ \\
\hline & $\begin{array}{l}\text { Основные формуулы: } \\
\text { - работа поля по пе- } \\
\text { ремешению зарада; } \\
\text {-энергил злектрн- } \\
\text { теского полл }\end{array}$ \\
\hline
\end{tabular}

подготовки в вузе, нацеленной на конечные результаты обучения $[6,7,8]$.

\section{СТРУКТУРНАЯ МОДЕЛЬ УМЕНИЯ}

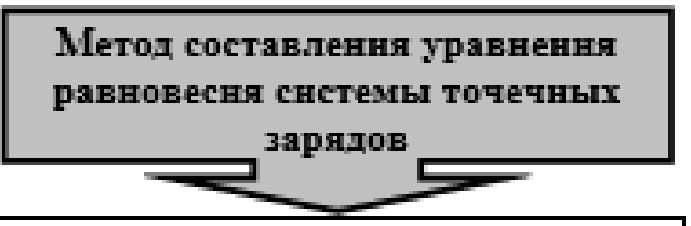

1. Сделать рисунок, на котором укззать все ситы, действугопне в cистемsе ити вектора напрякенности полей всех зарядов, координатные оси.

2. Составить уравнение равновесия системы в векторном виде

3. Cпроепировать векторное уравнение на координатные осп

4. 3aпrсать sатематинеское выраженне дпк кахқпого слагаеsьoro

5.Репить полуденную систезу уравнений относитепьно пскомых величин.

Метод ннтегрнровання по злементарным нстодннкам

1. Разделить зархкенный источник на бесконечно малые унастки, которые условно моккно синтать тонечныпм зарадампі

2. Записать математндеское вырақение рассматриваемой величины в днффференциальном виде

3. Интегрированием по тинит, поверхности или обьемгу найти сузммарное знадение данной велитины

4. Решить потуленное уравнение относительно искомпгх параметров

\section{Професснонально орнентнро-} ванная модель умення

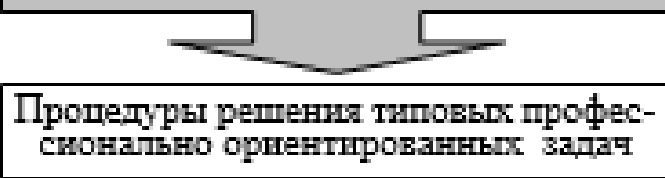

Рисунок 1 - Информационная модель по теме «Электрическая система первого вида».

Осуществление системного подхода к построению курса электродинамики и системнодеятельностного подхода к организации его усвоения способствует сокращению объема изучаемого материала при увеличении объема информации, получаемой студентами. Это достигается включением в содержание учебной дисциплины проблемных ситуаций, обеспечивающих мотивацию обучаемых, информационных моделей в виде схем ООД 
(ориентировочной основы деятельности) для уяснения учебного материала, обучающих заданий, для формирования на основе этих моделей познавательных, исследовательских и профессиональных знаний, умений и навыков, а также личностных качеств будущего специалиста $[9,10]$.

Одна из информационных моделей в виде схем ООД по курсу электродинамики представлена на рис. 1.
Результаты экспериментального обучения показывают, что содержание курса электродинами-ки, усвоенное на основе информационных моделей в виде системных схем ООД начинает выступать как органическая часть целостного содержания профессиональной подготовки специалиста, нести функцию теоретического фундамента знаний, дающего ориентировку в дальнейшей познавательной и профессио-нальной деятельности.

\section{References:}

1. Belyaev SA, Hvingiya TG (2013) Innovative pedagogical potential and its realization in the field of engineering and maritime education // Southern Federal University. Jurisprudence. 2013.-№3.

2. Balyaeva SA, AN Uglova (2014) Theoretical Foundations of pedagogic-ing innovation // State Ma-rine University Herald named Admiral FF Ushakov. Exploitation. Safety and economy Single water-way. - 2014. - №2 (7).

3. AN Uglova A (2015) comprehensive approach to the educational processes-sous maritime universi-ty. Proceedings of the international scientific-practical conference on September 17-19, 2015.: Modern trends and laws of the development dimension of transport and logistics complex of the Azov-Black Sea Novorossiysk basseyna.-: RIO LGU im.adm. Ushakov, 2015.

4. VS Gott (1977) The material unity of the world and the unity of scientific knowledge // Questions of philosophy. 1977.№12

5. AN Averyanov (1985) Systemic knowledge mira.-M.: 1985.

6. Reshetova ZA, Balyaeva SA (1985) One of the approaches to the construction of the discipline // Herald highest shkoly.1985.№1.
7. Balyaeva SA (2002) Formation of systems thinking as a condition of fundamental nature and the professionalization of assimilated knowledge (for example, the course "Theoretical Mechanics"). In the book .: Formation B tem of thought in education / Ed. Prof. BEHIND. Reshetova. - $\mathrm{M}$.: UNITY DA-NA 2002.

8. Mishchik SA (2014) Pedagogometrika and mathematical modeling educational activity. Materialy Mezhdunarodnoy nauchnoy konferenctsii "Modern mathematics in science" - 30.06.2014. ISJ Theoretical \&Applied Science 6(14): 54-56 Caracas, Venezuela. doi: http://dx.doi.org/10.15863/TAS.2014.06.14.10

9. Balyaeva SA, Borodina, LN, Uglova AN (2008) Psycho-pedagogical bases of construction of the dis-cipline in technical colleges // higher education segodnya.2008. Number 10.

10. Balyaeva SA, AN Uglova (2012) Improved obschena-Manual discharge preparation Marine industry pro-fessionals on the basis of innovative teaching-tion technologies // scientific problems of the humanities isinvestigations. Issue 5 - Pyatigorsk. - 2012. 